\title{
Obesity, obstructive sleep apnea and type 2 diabetes mellitus: Epidemiology and pathophysiologic insights
}

\begin{abstract}
Obesity is a major global health issue, and its prevalence is increasing. Obesity is associated with much comorbidity such as obstructive sleep apnea (OSA), type 2 diabetes mellitus (T2DM), and cardiovascular diseases (CVD). Obesity is also one of the major causative factors of OSA, and OSA itself can promote the onset of after T2DM because hypoxic episodes decrease insulin sensitivity, and activation of the sympathetic pathway leads to the release of inflammatory markers associated with insulin resistance. Continuous Positive Airway Pressure (CPAP) can be used to ameliorate both conditions, as CPAP decreased hypoxia episodes and increases insulin sensitivity and improves glucose metabolism. Weight-loss strategies play an important role in improving OSA, T2DM, and other associated comorbidities. Lifestyle modification of diet and exercise, medications or bariatric surgery should be considered weight loss. The purpose of this review is to describe the relationship between obesity, OSA, and T2DM.
\end{abstract}

Keywords: CPAP, OSA, T2DM, bariatric surgery, diabetes mellitus, obesity, obstructive sleep apnea, hyperglycaemia
Volume 2 Issue 3 - 2018

Shazia Jehan,' Alyson K Myers, ${ }^{2}$ Ferdinand

Zizi,' Seithikurippu R Pandi-Perumal, ${ }^{3}$

Girardin Jean-Louis,' Samy I McFarlane ${ }^{4}$

'Department of Population Health, New York University School of Medicine, USA

${ }^{2}$ Department of Medicine, North Shore University Hospital, USA

${ }^{3}$ Somnogen Canada Inc, Canada

${ }^{4}$ Department of Medicine, SUNY Downstate Medical Center, USA

Correspondence: Samy I Mc Farlane, Distinguished Teaching Professor of Medicine/ Endocrinology, Associate Dean, College of Medicine, Internal Medicine Residency Program Director, State University of New York, Downstate Medical Center 450 Clarkson Avenue, Box 50,Brooklyn, I 1203209 8, USA, Tel 7I827067 07, Fax 7182-7044-88,Email smcfarlane@downstate.edu

Received: March 15, 2018 | Published: June 21, 2018
Abbrevations: OSA, obstructive sleep apnea; T2DM, Type 2 diabetes mellitus; CPAP, continuous positive airway pressure; NASH, non-alcoholic steatohepatitis; AHI, apnea-hypopnea index; ESS, epworth sleepiness scale

\section{Introduction}

Obesity is now epidemic which has tripled worldwide since $1975^{1}$ yet it was only recently recognized as a disease by the United States in 2013. ${ }^{2}$ With this change in definition came the ability for physicians to bill for services for obesity counselling and therapy. Obesity is the precipitating factor for many diseases such as CVD, OSA, T2DM, Non-alcoholic steatohepatitis (NASH), osteoarthritis (OA) and some cancers (i.e. colon, prostate and breast). ${ }^{1,3}$ Having obesity as well as one of these co-morbid conditions can increase the risk of further disease even more. This can be seen in the relationship between obesity, OSA, and T2DM. The OSA is one of the major causative factors of sleep disturbance and it is also commonly found in patients diagnosed with T2DM because it's associated with glucose intolerance and insulin resistance. This association is even greater when OSA associated with obesity. In the SLEEP-AHEAD study of lifestyle modification in obese people with T2DM, increasing waist circumference was the only positive predictor for the diagnosis of sleep apnea, and BMI was a positive predictor for severe OSA. As a result, weight loss is an important part of the management of those with obesity, T2DM, and OSA. Physicians need to be aware of the need to screen for T2DM in obese patients with OSA especially those with severe OSA, as they are at risk for T2DM regardless of BMI or waist circumference. ${ }^{5}$
The relationship between obesity,T2DM, and OSA $^{6}$

\section{Pathogenesis of obesity and T2DM}

Between 2013 and 2014, the prevalence of obesity in the United States was $35 \%$ for men and $40.4 \%$ for women. ${ }^{4}$ In a cross-sectional analysis of National Health and Nutrition Examination Survey (NHANES) data, rural whites and blacks had greater rates of obesity than their urban counterparts. ${ }^{7}$ The National Health and Nutrition Examination Survey (NHANES) III data has also demonstrated that obesity increases the risk of T2DM amongst blacks, whites, and Mexican-Americans. ${ }^{5}$ The T2DM is a condition of insulin resistance leading to hyperglycaemia. Abdominal obesity can predispose to this state of insulin resistance through the release of pro-inflammatory cytokines and non-esterified fatty acids. ${ }^{8}$ In a study of incident T2DM, African-American women who were obese were at greater risk for developing T2DM over time than a White woman; obesity was noted as a modifiable risk, which could reduce the risk. ${ }^{9}$ Greater BMI can also be associated with increased morbidity in elderly white people with T2DM. ${ }^{10}$ This was also seen in East African blacks. ${ }^{11}$ Interestingly enough, the connection between obesity and T2DM is different in Asian populations; as visceral obesity and waist circumference, not body mass index (BMI) are risk factors for T2DM.

\section{Pathogenesis of obesity and OSA}

Obesity contributes to OSA as increased neck fat leads to obstruction of the upper airway during sleep. ${ }^{13}$ In addition, lying in a recumbent fashion and increased abdominal girth leads to a 
decrease in lung volume thus further worsening hypoxia. ${ }^{14}$ OSA is also characterized by neuronal dysfunction of the muscles needed to maintain the upper airway patent during sleep. It is not clear if obesity plays a role in this.

In an observational study of mostly white older adults, those with a BMI over 30 had a hazards ratio of $1.48(1.02$ to 2.15$)(\mathrm{p}<0.05)$ to have self-reported OSA when compared to those who were normal weight; however this effect was not significant when the overweight adults were compared to the normal weight adults. ${ }^{10}$ Male gender also increases the risk of OSA as rates of OSA are greater in men when compared to women, for unclear reasons this difference decreases in post-menopausal women. ${ }^{15,16}$

Obesity and OSA can also be independently associated with an increased risk of cardiovascular disease. In a cohort of an adult cohort of people referred for polysomnography, the risk of developing atrial fibrillation increases as the severity of the apnea-hypopnea index worsens or by a greater BMI. ${ }^{17}$ Other associated co-morbidities include hypertension, depression and gastric reflux. ${ }^{18}$

\section{The relationship between OSA and T2DM}

\section{Pathophysiology}

The relationship between OSA and T2DM is bidirectional: T2DM is a risk factor for OSA and OSA is a risk factor for T2DM. Even in people with pre-diabetes and morbid obesity, there is a twofold increased rate of OSA compared to morbid obese controls with normoglycemia. ${ }^{19}$ When hypoxic episodes and sleep fragmentation occur in OSA several hormonal changes occur leading to activation of the sympathetic nervous system and increased the release of catecholamine, thus leading to glycogenesis and decreased insulin sensitivity. ${ }^{20}$ In addition, there is stimulation of the hypothalamicpituitary-adrenal axis (HPA axis) leading to increased levels of cortisol which can further impair glucose metabolism by decreasing insulin release. ${ }^{21,22}$ Oxidative stress and inflammatory markers (i.e. TNF $\alpha$, IL6), ${ }^{23}$ play an important role in the cascade of inflammatory processes which ultimately lead to metabolic syndrome. OSA itself is also associated with increased levels of free leptin ${ }^{24}$ due to low levels of its soluble leptin receptor (sOb-R). This state of leptin resistance is also associated with insulin resistance independent of BMI. ${ }^{25}$ Adiponectin, secreted by adipose cells increases insulin sensitivity but its levels are decreased in the milieu of hypoxia. ${ }^{26}$

In cross-sectional analyses of obese people, severity or frequency of apnea or minimum oxygen saturation, not BMI as predictors of insulin resistance. ${ }^{27-29}$ In a meta-analysis including 5953patients with OSA over a 2-16 years duration, there were 332 incident cases of T2DM..$^{30}$ The risk was greater in those with moderate to severe OSA. In a cross-sectional analysis of adults, both the normal weight and overweight/obese people with sleep-disordered breathing (SDB) had greater rates of pre-diabetes or diabetes when compared to those without SDB. ${ }^{31}$ Interestingly enough, this link was not always seen in longitudinal studies examining this association. ${ }^{32}$ In a prospective study of Swedish men aged 30-69, OSA was only a risk factor for T2DM in those who were obese, but not in those with OSA and normal weight. ${ }^{33}$ The Wisconsin Sleep study found no statistically significant increased risk of incident diabetes for 8 years at any level of Apnea-Hypopnea Index (AHI) when results were adjusted for age, sex and body habitus. ${ }^{34}$

Visceral fat has been associated with increased risk of T2DM in those with OSA. ${ }^{24}$ In a study of obese people with T2DM who chronically sleep less than 6.5 hours per night, those with OSA had greater amounts of visceral fat, as well as increased levels of IL-6, IFN- $\gamma$ and TNF- $\alpha$ compared to those without OSA. ${ }^{27}$ In another, waist but not neck circumference was seen as an associated risk for OSA in obese people with $\mathrm{T} 2 \mathrm{DM} ;{ }^{4}$ but another observational study of people with OSA demonstrated that neck circumference, older age, male gender, and elevated resting heart rate, prior myocardial infarction or hypertension were associated with incident T2DM. ${ }^{36}$ Co-morbid hypertension has also been associated with insulin resistance in those with $\mathrm{OSA}^{37}$. It must be noted that there is great heterogeneity in these studies, as some of them used self-report as opposed to formal testing for the diagnoses of both T2DM and OSA. Also, many of them mostly enrolled males, so further research needs to be conducted in women. ${ }^{38}$

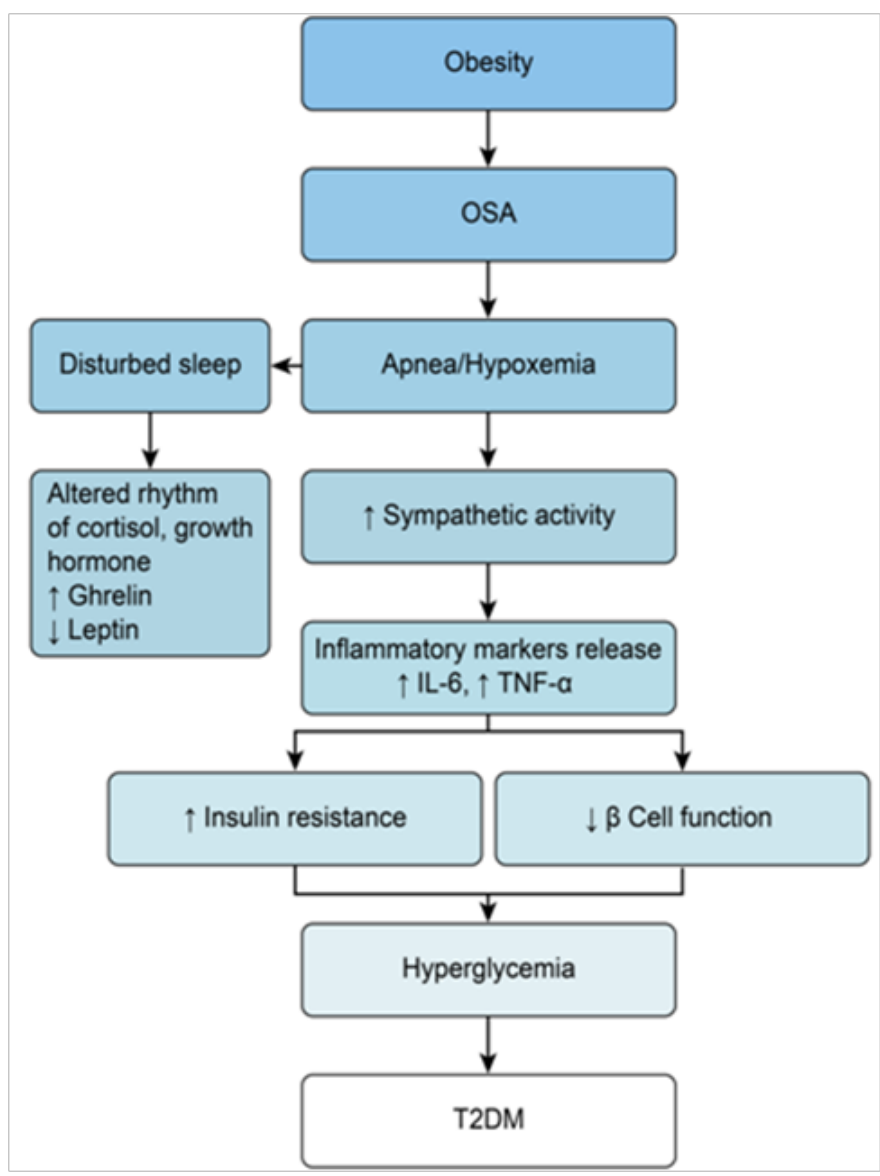

Figure I Interrelated pathophysiology of Obesity, OSA, and T2DM.

\section{Prevalence and screening}

Patients with T2DM have an increased risk of OSA, unfortunately, many are undiagnosed. In 2008 the International Diabetes Federation Task Force on Epidemiology and Prevention issued a report noting that patients with T2DM should be assessed for snoring, daytime sleepiness and witnessed apnoeic events. ${ }^{39}$ Snoring can be used as a screening question, but it is not perfect as there are people who snore who can have an Apnea-hypopnea Index (AHI) in the normal range. ${ }^{40}$ Also, co-morbid pain from conditions such as diabetic neuropathy can interfere with achieving a good night sleep ${ }^{41} \mathrm{~A}$ study in primary care with T2DM yielded a diagnosis of OSA in only $18 \%$ of patients 
which was far less than the $87 \%$ expected from prior studies. ${ }^{42,43}$ Highrisk patients, such as those with obesity and pre-diabetes/diabetes should be considered. ${ }^{19}$ It must be noted that many of these at-risk patients may be asymptomatic. ${ }^{44}$ Weight or BMI should not be the sole measurements considered as they do not account for the distribution of body fat or variance in cephalometric measurements such as the size of the tongue or soft palate. ${ }^{45}$ Overnight sleep studies at a sleep center or home devices can be used to diagnose OSA. The advantage of a home screening device is the ease of use, short set-up time and low cost. ${ }^{46}$
The other benefit of screening for OSA in this population is that there is evidence that suggests that in select populations, glycaemic control is associated with abnormalities of sleep. In severely obese patients, those with T2DM had the lowest oxygen saturation levels and had the greatest percentage of time with an oxygen saturation of less than $90 \%(\% \mathrm{TST}<90 \%)$ during overnight polysomnography. ${ }^{47}$ These individuals had higher Haemoglobin A1C (HbA1C) levels, but AHI did not have an effect on glycaemic control ${ }^{47}$ In a study of men with BMI, less than $40 \mathrm{~kg} / \mathrm{m}^{2}$ referred to a sleep clinic due to snoring, the severity of AHI was associated with elevated post-load glucose levels and lower insulin sensitivity ${ }^{49}$ (Table 1).

Table I Correlation of OSA, Obesity, and T2DM

\begin{tabular}{|c|c|c|c|c|c|c|}
\hline Nature of study & Study design & $\mathbf{N}$ & OSA & Obesity & T2DM & References \\
\hline $\begin{array}{l}\text { Quality of sleep and risk for OSA in ambulant } \\
\text { individuals with T2DM at a tertiary referral } \\
\text { hospital in Kenya }\end{array}$ & $\begin{array}{l}\text { Cross-sectional, } \\
\text { comparative study }\end{array}$ & 223 & positive & positive & positive & 48 \\
\hline Comorbidities Associated with OSA & retrospective study & 100 & positive & Positive & positive & 18 \\
\hline $\begin{array}{l}\text { Sleep apnoea in Australian men: disease burden, } \\
\text { co-morbidities, and correlates from the } \\
\text { Australian males. }\end{array}$ & Longitudinal study & 13,423 & Positive & Positive & Positive & 93 \\
\hline $\begin{array}{l}\text { Prevalence of diagnosed sleep apnea among } \\
\text { patients with type } 2 \text { diabetes in primary care. }\end{array}$ & Retrospective & 16,066 & Positive & Positive & Positive & 42 \\
\hline $\begin{array}{l}\text { Prevalence of glucose intolerance and } \\
\text { associated risk factors in rural and urban } \\
\text { populations of different ethnic groups in Kenya. }\end{array}$ & cross-sectional study & 1459 & Positive & Positive & positive & 11 \\
\hline OSA among obese patients with T2DM & logistic regressions & 306 & Positive & Positive & positive & 4 \\
\hline $\begin{array}{l}\text { Impaired glucose-insulin metabolism in males } \\
\text { with OSAS }\end{array}$ & cross-sectional study & 595 & Positive & Positive & Positive & 49 \\
\hline
\end{tabular}

\section{The effect of ethnicity on OSA, Obesity, and T2DM}

In Asian population, a BMI greater than $23 \mathrm{~kg} / \mathrm{m}^{2}$ is used to distinguish overweight status and greater than $28 \mathrm{~kg} / \mathrm{m}^{2}$ to denote obesity. Vats et al., ${ }^{50}$ argue that obesity is a growing problem in the Middle East, but the scarcity of sleep centres limits data collection. ${ }^{50}$ In a comparison of White Europeans to South Asians, White Europeans had greater rates of OSA due to greater rates of obesity and central adiposity in White Europeans. ${ }^{51,52}$ In a study of Korean patients having polysomnography without a history of T2DM, those with the highest rate of T2DM or IFG(impaired fasting glucose) had a mean BMI of $27 \mathrm{~kg} / \mathrm{m}^{2} .^{53}$ As a result, Asian patients will be at risk for OSA and T2DM at a lower BMI, suggesting that neck circumference, BMI, and central adiposity are not to blame for OSA in Asian populations. ${ }^{54,55} \mathrm{It}$ has been suggested that racial differences in craniofacial anatomy may explain the risk of OSA in Asians who are not obese. ${ }^{33}$ Craniofacial anatomy may also explain the greater rate of increased apneics activity in African-Americans as compared to whites due to tonsillar hypertrophy. ${ }^{56}$ In a study of Kenyans in a diabetes clinic, those with older age (age over 65), larger waist circumference and poor sleep quality were at greater risk for sleep apnea as determined by their score on the Berlin questionnaire SMR(sensori motor rhythms). ${ }^{48}$

\section{Management of OSA and co-morbid T2DM Lifestyle modification}

Lifestyle interventions aimed at decreasing caloric intake and increasing physical activity can have varying effects on AHI and metabolic indices. A Finnish study of mild OSA patients randomized to a 1 year intervention of 14 sessions with a clinical dietician and a 12 week very low-calorie diet, demonstrated improvements in weight, AHI, and glycaemic control when compared to those who had no intervention. ${ }^{57}$ Two of the four patients in the intervention arm were able to stop their diabetes medications and two people in the control arm were initiated on diabetes medications. Lifestyle modifications such as reduction in caloric intake and 175 minutes of moderate exercise weekly can lead to improved outcomes in $\mathrm{HbA} 1 \mathrm{c}$, but not AHI in those with T2DM and OSA. ${ }^{58}$ This effect of improved HbA1c was greater in the intensive lifestyle group when compared to those who received 3 sessions of the group and individual diabetes education. Also, during this four-year study, remission of OSA was $20.7 \%$ in the intervention group compared to only $3.6 \%$ in the diabetes education group. ${ }^{58}$ Unfortunately, many regained half of the weight loss between years 2 and 4 as the lifestyle intervention was only promoted in year 1; despite this, the average AHI did not worsen. ${ }^{58}$ As a result, improvement in AHI is independent of weight loss. Weight loss can 
be difficult if OSA is not well-managed as the daytime sleepiness will deter patients from increasing physical activity. ${ }^{16}$

\section{Bariatric surgery}

Bariatric surgery has become a management option to cure components of the metabolic syndrome in obese patients. For obese patients without a diagnosis of OSA, a screening polysomnography is recommended as $83 \%$ of persons (289/349) who scored over 6 on the Epworth Sleepiness Scale (ESS) had OSA confirmed by polysomnography. ${ }^{60}$ Metabolic outcomes such as the resolution of T2DM and/or OSA after bariatric surgery are variable. In a metaanalysis of 136 studies ( $\mathrm{n}=22,094$ patients) which looked at co-morbid health outcomes in those who had bariatric surgery for weight loss, $87.9 \%(1051 / 1195)$ and $76.8 \%(1417 / 1846)$ had a resolution of OSA and T2DM respectively. ${ }^{61}$ In a study of obese patients with moderatesevere OSA, those who were randomized to a laparoscopic lap band lost more weight than those given a conventional plan of diet and exercise. Despite this greater weight loss, there was not a significant change in AHI. ${ }^{62}$ Those with a shorter duration of diabetes (less than 5-10 years) or those on oral agents had a nearly 2 -fold greater chance of having a resolution of their T2DM than those with disease greater than 10 years or those taking insulin. ${ }^{63}$

\section{Continuous positive airway pressure}

There have been mixed results examining the effect of Continuous Positive Airway Pressure (CPAP) on improving insulin sensitivity in obese individuals without diabetes. 9 patients with T2DM and moderate to severe OSA had no changes in insulin sensitivity measurements after 2 nights of CPAP; however, an improvement was seen after 3 months of CPAP. ${ }^{64}$ In a study of 60 Chinese men with moderate to severe sleep apnea, those who used 1 week of nasal CPAP had improved insulin sensitivity in obese individuals without T2DM. ${ }^{6}$ This effect was even seen 12 weeks later in those who were obese. Interestingly enough in a study of patients with OSA without diabetes, those who underwent a 2 week withdrawal period from CPAP had worsening measures and symptoms of OSA, heart rate and blood pressure, but no changes in insulin resistance. ${ }^{66}$ The fact that only $20 \%$ of patients in the study had T2DM is likely the reason for this finding. A similar finding was seen in an observational study from the VA(Veteran Affairs) in which those with the two highest quartiles of OSA severity had a lower incidence of T2DM if they were compliant with CPAP use. ${ }^{67}$

When CPAP was added to lifestyle intervention, there was a significant improvement in OGTT outcomes after 12 months as compared to those with only lifestyle coaching. There was no significant difference in weight loss between the 2 groups, but those in the CPAP with intervention had greater rates of resolution of metabolic indices ${ }^{68}$ In a randomized, parallel 6 month trial examining the effects of CPAP on inflammatory markers, insulin sensitivity and lipids, there was no clinically significant reduction in CRP after 24 weeks between the CPAP alone, weight loss intervention or CPAP+ weight loss intervention groups. ${ }^{69}$ Insulin sensitivity and triglycerides however significantly improved in the weight loss and CPAP+ weight loss arms when compared to CPAP alone. Another study showed greater improvement in leptin levels, but no difference in insulin sensitivity in obese patients with severe OSA who used their CPAP 6 hours/night or more compared to those who used it 2 hours or less. ${ }^{70}$

Treatment with CPAP therapy can yield mixed results in improvement of diabetic measures in those with OSA and pre-diabetes or diabetes. In a study of patients with pre-diabetes and OSA, use of CPAP for 8hours/night for 2 weeks led to improved responses to OGTT when compared to those who received a placebo. ${ }^{71} \mathrm{CPAP}$ usage for greater than 4 hours/ for 30-90days led to significantly improved $\mathrm{HbA} 1 \mathrm{C}$ and post-prandial glucose measurements in those with T2DM and newly diagnosed OSA. ${ }^{72}$ The presence of a leak around the seal of the mask can decrease adherence to CPAP therapy. ${ }^{73-75}$ Unfortunately, the significance of these results was limited by the lack of control group. In a small study of patients $(n=31)$ with a BMI over $35 \mathrm{~kg} / \mathrm{m}$ and T2DM, insulin resistance declined with CPAP use. ${ }^{76}$

CPAP use also can potentially affect the outcomes of cardiovascular risk and mortality. Those in the Wisconsin Sleep study with severe OSA who were not regular users of CPAP had a 5-fold greater risk of cardiovascular mortality compared to those with severe OSA who used CPAP. ${ }^{77}$ This increased risk occurred in the setting of co-morbid conditions such as hypertension, diabetes or known coronary artery disease. This increased risk has been disputed in a meta-analysis of 10 randomized controlled trials comparing CPAP to sham use ?? The authors noted that the lack of change in cardiovascular risk factors like blood pressure or diabetes and the short-term nature of these studies were likely causes of this result. ${ }^{78}$

\section{Discussion}

The relationship between disturbed sleep and incident T2DM has a U-shaped relationship, in which those who get less than 5 hours or greater than 9 hours of sleep are at greater risk. ${ }^{79}$ Disturbed sleep is associated with insulin resistance, thus increasing the risk for T2DM. T2DM itself is associated with obesity and co-morbid pain such as neuropathy. This increases the risk for disturbed sleep. As a result, those with T2DM should be screened for OSA, and the converse is also true. Sleep disturbance and obesity are risk factors for the other components of the metabolic syndrome, thus hypertension, dyslipidemia, and risk for cardiovascular disease should also be assessed.

Obesity is increasing globally and the associated diseases, OSA and T2DM prevalence is also increasing globally. ${ }^{80,81}$ OSA and T2DM are common findings in patients. ${ }^{82}$ OSA is a risk factor for T2DM, metabolic syndrome and cardiovascular diseases ${ }^{80,81}$ One more Cohort study shows moderate to severe OSA is one of the major risk factor in causing incidental T2DM. ${ }^{83}$ Moderate to severe OSA increases blood sugar level in T2DM patients, because hypoxemia triggers hyperglycaemia in patients with T2DM along with OSA ${ }^{84}$ OSA can worsen hyperglycaemia in T2DM patients, and can be the only major causative factor of T2DM. ${ }^{85}$ In severe OSA patients hypoxemia increases blood sugar level and can aggravate pre-existing T2DM. Patient should be screened for DT2M if present with OSA and vice versa.$^{86}$ OSA causes hyperglycaemia and it depends on the severity of OSA; severe OSA is also associated with insulin resistance..$^{87,88}$ OSA is one of the major leading factors causing, hypertension, T2DM, metabolic syndrome, and cardiovascular diseases. ${ }^{89}$

Patients with obesity and diabetes should be screened for OSA for better health outcomes as OSA is associated with diabetes and obesity and can lead to metabolic and cardiovascular complications in these patients. ${ }^{45} \mathrm{CPAP}$ treatment in OSA patients associated with T2DM can significantly improve hyperglycemia by improving insulin sensitivity and there could be a significant improvement in T2DM symptoms. ${ }^{90-92}$ More long-term studies need to be conducted to further examine this relationship between OSA and T2DM, as most of the literature is based on cross-sectional data. ${ }^{40}$ 


\section{Conclusion}

Obesity, OSA, and T2DM are associated as they all are associated with alterations of inflammatory markers and increase the risk of cardiovascular disease. The management strategy of these conditions includes weight loss. Weight loss can be achieved through lifestyle modification: increased physical activity and decreased caloric intake and/or bariatric surgery. CPAP therapy is also a gold standard for the treatment of hypoxia in those with moderate to severe OSA. More studies need to be done assessing the use of CPAP in conjunction with weight loss for improving outcomes in those with T2DM and OSA. In addition, long-term studies need to be done to see the impact of weight loss and CPAP on the improvements of AHI and insulin resistance.

\section{Acknowledgments}

This work is supported by the following funding agencies: R25-HL105444 and R25-HL 116378 (NHLBI); R01-MD007716 (NIMHD) to GJL. However, the funders had no role in study design, data collection, analysis and decision to publish.

\section{Conflict of interest}

The author declares that there are no conflicts of interest.

\section{References}

1. World Health Organization. WHO Obesity and overweight: fact sheet. Geneva: World Health Organization; 2011.

2. Pollack A. A.M.A.Recognizes Obesity as a Disease. 2013.

3. Wilson PF, Bozeman SR, Burton TM, et al. Prediction of First Events of Coronary Heart Disease and Stroke with Consideration of Adiposity. Circulation. 2008;118(2):124-130.

4. Foster GD, Sanders MH, Millman R, et al. Obstructive sleep apnea among obese patients with type 2 diabetes. Diabetes care. 2009;32(6):1017-1019.

5. Must A, Spadano J, Coakley EH, et al. The disease burden associated with overweight and obesity. JAMA. 1999;282(16):1523-1609.

6. Nagayoshi M, Punjabi NM, Selvin E, et al. Obstructive sleep apnea and incident type 2 diabetes. Sleep Med. 2016;25:156-161.

7. Befort CA, Nazir N, Perri MG. Prevalence of obesity among adults from rural and urban areas of the United States: findings from NHANES (2005-2008). J Rural Health. 2012;28(4):392-397.

8. Kahn SE, Hull RL, Utzschneider KM. Mechanisms linking obesity to insulin resistance and type 2 diabetes. Nature. 2006;444(7121):840-846.

9. Brancati FL, Kao WL, Folsom AR, et al. Incident type 2 diabetes mellitus in African American and white adults: the Atherosclerosis Risk in Communities Study. JAMA. 2000;283(17):2253-2259.

10. Janssen I. Morbidity and mortality risk associated with an overweight BMI in older men and women. Obesity (Silver Spring). 2007;15(7):1827-1840.

11. Christensen DL, Friis H, Mwaniki D, et al. Prevalence of glucose intolerance and associated risk factors in rural and urban populations of different ethnic groups in Kenya. Diabetes Res Clin Pract. 2009;84(3):303-310.

12. Chen L, Magliano DJ, Zimmet PZ. The worldwide epidemiology of type 2 diabetes mellitus - present and future perspectives. Nat Rev Endocrinol.2011;8(4):228-236.
13. Schwartz AR, Patil SP, Laffan AM, et al. Obesity and obstructive sleep apnea: pathogenic mechanisms and therapeutic approaches. Proc Am Thorac Soc. 2008;5(2):185-192.

14. Dempsey JA, Veasey SC, Morgan BJ, et al. Pathophysiology of sleep apnea. Physiol Rev. 2010;90(1):47-112.

15. Peppard PE, Young T, Barnet JH, et al. Increased prevalence of sleepdisordered breathing in adults. Am J Epidemiol. 2013;177(9):1006-1014.

16. Pillar G, Shehadeh N. Abdominal fat and sleep apnea. Diabetes care. 2008;31(Supplement 2):S303-S309.

17. Gami AS, Hodge DO, Herges RM, et al. Obstructive sleep apnea, obesity, and the risk of incident atrial fibrillation. $J \mathrm{Am}$ Coll Cardiol.2007;49(5):565-571

18. Pinto JA, Ribeiro DK, Da Silva Cavallini AF, et al. Comorbidities associated with obstructive sleep apnea: a retrospective study. Int Arch Otorhinolaryngol. 2016;20(02):145-150.

19. Fredheim JM, Rollheim J, Omland T. Type 2 diabetes and pre-diabetes are associated with obstructive sleep apnea in extremely obese subjects: a cross-sectional study. Cardiovasc Diabetol. 2011;10:84.

20. Aurora RN, Punjabi NM. Obstructive sleep apnoea and type 2 diabetes mellitus: a bidirectional association. Lancet Respir Med. 2013;1(4):329-338.

21. Punjabi NM, Polotsky VY. Disorders of glucose metabolism in sleep apnea. J Appl Physiol. 2005;99(5).

22. Kent BD, Mc Nicholas WT, Ryan S. Insulin resistance, glucose intolerance and diabetes mellitus in obstructive sleep apnoea. $J$ Thorac Dis. 2015;7(8):1343-1357.

23. Vgontzas AN, Papanicolaou DA, Bixler EO, et al. Elevation of plasma cytokines in disorders of excessive daytime sleepiness: role of sleep disturbance and obesity. $J$ Clin Endocrinol Metab. 1997;82(5):1313-1316.

24. Vgontzas AN, Papanicolaou DA, Bixler EO, et al. Sleep apnea and daytime sleepiness and fatigue: relation to visceral obesity, insulin resistance, and hypercytokinemia. J Clin Endocrinol Metab. 2000;85(3):1151-1158.

25. Sandhofer A, Laimer M, Ebenbichler CF, et al. Soluble leptin receptor and soluble receptor $\square$ bound fraction of leptin in the metabolic syndrome. Obes Res. 2003;11(6):760-768.

26. Doumit J, Prasad B. Sleep Apnea in type 2 diabetes. Diabetes Spectrum 2016;29(1):14-19.

27. Ip MS, Lam B, $\mathrm{Ng} \mathrm{MM}$, et al. Obstructive sleep apnea is independently associated with insulin resistance. Am J Respir Crit Care Med. 2002;165(5):670-676.

28. Punjabi NM, Sorkin J D, Katzel LI, et al. Sleep-disordered breathing and insulin resistance in middle-aged and overweight men. Am J Respir Crit Care Med. 2002;165(5):677-682

29. Tiihonen M, Partinen M, Narvanen S. The severity of obstructive sleep apnoea is associated with insulin resistance. J Sleep Res 1993;2(1):56-61.

30. Wang X, Bi Y, Zhang Q, et al. Obstructive sleep apnoea and the risk of type 2 diabetes: a meta $\square$ analysis of prospective cohort studies. Respirology. 2013;18(1):140-146.

31. Seicean S, Kirchner HL, Gottlieb DJ, et al. Sleep-disordered breathing and impaired glucose metabolism in normal-weight and overweight/ obese individuals. Diabetes Care. 2008;31(5):1001-1006.

32. Tasali E, Ip MS. Obstructive sleep apnea and metabolic syndrome: 
alterations in glucose metabolism and inflammation. Proc Am Thorac Soc. 2008;5(2):207-217.

33. Elmasry A, Janson C, Lindberg E, et al. The role of habitual snoring and obesity in the development of diabetes: a $10 \square$ year follow $\square$ up study in a male population. J Intern Med. 2000;248(1):13-20.

34. Reichmuth KJ, Austin D, Skatrud JB, et al. Association of sleep apnea and type II diabetes: a population-based study. Am J Respir Crit Care Med. 2005;172(12):1590-1595.

35. Cizza G, Piaggi P, Lucassen EA, et al. Obstructive sleep apnea is a predictor of abnormal glucose metabolism in chronically sleep deprived obese adults. PloS One. 2013;8(5):e65400.

36. Kendzerska T, Gershon AS, Hawker G, et al. Obstructive sleep apnea and incident diabetes. A historical cohort study. Am J Respir Crit Care Med. 2014;190(2):218-225.

37. Chasens ER, Weaver TE, Umlauf MG. Insulin resistance and obstructive sleep apnea: is increased sympathetic stimulation the link? Biol Res Nurs. 2003;5(2):87-96.

38. Pamidi S, Aronsohn RS, Tasali E. Obstructive sleep apnea: role in the risk and severity of diabetes. Best practice \& research. Best Pract Res Clin Endocrinol Metab. 2010;24(5):703-715.

39. Shaw JE, Punjabi NM, Wilding JP, et al. Sleep-disordered breathing and type 2 diabetes: a report from the International Diabetes Federation Taskforce on Epidemiology and Prevention. Diabetes Res Clin Pract. 2008;81(1):2-12.

40. Young T, Palta M, Dempsey J, et al. The occurrence of sleepdisordered breathing among middle-aged adults. $N$ Engl J Med. 1993;328(17):1230-1235.

41. Knutson KL, Ryden AM, Mander BA, et al. Role of sleep duration and quality in the risk and severity of type 2 diabetes mellitus. Arch Intern Med. 2006;166(16):1768-1774.

42. Heffner JE, Rozenfeld Y, Kai M, et al. Prevalence of diagnosed sleep apnea among patients with type 2 diabetes in primary care. Chest. 2012;141(6):1414-1421

43. Idris I, Hall AP, O'Reilly J, et al. Obstructive sleep apnoea in patients with type 2 diabetes: aetiology and implications for clinical care. Diabetes Obes Metab. 2009;11(8):733-741.

44. West SD, Nicoll DJ, Stradling JR. Prevalence of obstructive sleep apnoea in men with type 2 diabetes. Thorax. 2006;61(11):945-950.

45. Seetho IW, Wilding JP. Screening for obstructive sleep apnoea in obesity and diabetes--potential for future approaches. Eur J Clin Invest. 2013;43(6):640-655.

46. Einhorn D, Stewart D, Erman M, et al. Prevalence of sleep apnea in a population of adults with type 2 diabetes mellitus. Endocr Pract. 2007;13(4):355-362.

47. Leong WB, Banerjee D, Nolen M, et al. Hypoxemia and glycemic control in type 2 diabetes mellitus with extreme obesity. The J Clin Endocrinol Metab. 2014;99(9):E1650-E1654.

48. Sokwalla SMR, Joshi MD, Amayo EO, et al. Quality of sleep and risk for obstructive sleep apnoea in ambulant individuals with type 2 diabetes mellitus at a tertiary referral hospital in Kenya: a cross-sectional, comparative study. BMC Endocr Disord. 2017;17(1):7.

49. Meslier N, Gagnadoux F, Giraud P, et al. Impaired glucose-insulin metabolism in males with obstructive sleep apnoea syndrome. Eur Respir J. 2003;22(1):156-160.
50. Vats MG, Mahboub BH, Al Hariri H, et al. Obesity and Sleep-Related Breathing Disorders in Middle East and UAE. Canadian Respiratory Journal.2016.

51. Amin A, Ali A, Altaf Q, et al. Prevalence and Associations of Obstructive Sleep Apnea in South Asians and White Europeans with Type 2 Diabetes: A Cross-Sectional Study. J Clin Sleep Med. Official publication of the American Academy of Sleep Medicine. 2017;13(4):583-589.

52. Tahrani AA. Obstructive sleep apnoea in diabetes: Does it matter? Diabetes \& Vascular Disease Research. 2017;14(5):454-462.

53. Tamura A, Kawano Y, Watanabe T, et al. Relationship between the severity of obstructive sleep apnea and impaired glucose metabolism in patients with obstructive sleep apnea. Respir Med. 2008;102(10):1412-1416.

54. Ip MS, Lam B, Tang LC, et al. A community study of sleep-disordered breathing in middle-aged Chinese women in Hong Kong: prevalence and gender differences. Chest. 2004;125(1):127-134.

55. Iyer S. Sleep and type 2 diabetes mellitus-clinical implications. J Assoc Physicians India. 2012;60:42-47.

56. Redline S, Tishler PV, Hans MG, et al. Racial differences in sleepdisordered breathing in African-Americans and Caucasians. Am J Respir Crit Care Med. 1997;155(1):186-192.

57. Tuomilehto HP, Seppa JM, Partinen MM, et al. Lifestyle intervention with weight reduction: first-line treatment in mild obstructive sleep apnea. Am J Respir Crit Care Med. 2009;179(4):320-327.

58. Shechter A, Foster GD, Lang W, et al. Effects of a lifestyle intervention on REM sleep $\square$ related OSA severity in obese individuals with type 2 diabetes. J Sleep Res. 2017;26(6):747-755.

59. Kuna ST, Reboussin DM, Borradaile KE, et al. Long-term effect of weight loss on obstructive sleep apnea severity in obese patients with type 2 diabetes. Sleep. 2013;36(5):641-649.

60. Haines KL, Nelson LG, Gonzalez R, et al. Objective evidence that bariatric surgery improves obesity-related obstructive sleep apnea. Surgery. 2007;141(3):354-358

61. Buchwald H, Avidor Y, Braunwald E, et al. Bariatric surgery: a systematic review and meta-analysis. JAMA. 2004;292(14):1724-1737.

62. Dixon JB, Schachter LM, O’Brien PE, et al. Surgical vs conventional therapy for weight loss treatment of obstructive sleep apnea: a randomized controlled trial. JAMA. 2012;308(11):1142-1149.

63. Schauer PR, Burguera B, Ikramuddin S, et al. Effect of laparoscopic Roux-en Y gastric bypass on type 2 diabetes mellitus. Ann Surg. 2003;238(4):467.

64. Harsch IA, Schahin SP, Brückner K, et al. The effect of continuous positive airway pressure treatment on insulin sensitivity in patients with obstructive sleep apnoea syndrome and type 2 diabetes. Respiration. 2004;71(3):252-259.

65. Lam JC, Lam B, Yao T,et al. A randomised controlled trial of nasal continuous positive airway pressure on insulin sensitivity in obstructive sleep apnoea. Eur Respir J. 2010;35(1):138-145.

66. Kohler M, Ayers L, Pepperell JC, et al. Effects of continuous positive airway pressure on systemic inflammation in patients with moderate to severe obstructive sleep apnoea: a randomised controlled trial. Thorax. 2009;64(1):67-73.

67. Botros N, Concato J, Mohsenin V, et al. Obstructive sleep apnea as a risk factor for type 2 diabetes. The American journal of medicine. 2009;122(12):1122-1127. 
68. Salord N, Fortuna AM, Monasterio C, et al. A randomized controlled trial of continuous positive airway pressure on glucose tolerance in obese patients with obstructive sleep apnea. Sleep. 2016;39(1):35-41.

69. Chirinos JA, Gurubhagavatula I, Teff K. CPAP, weight loss, or both for obstructive sleep apnea. New England Journal of Medicine. 2014;370(24):2265-2275.

70. Trenell M, Ward J, Yee B, et al. Influence of constant positive airway pressure therapy on lipid storage, muscle metabolism and insulin action in obese patients with severe obstructive sleep apnoea syndrome. Diabetes Obes Metab. 2007;9(5):679-687.

71. Pamidi S, Wroblewski K, Stepien M, et al. Eight hours of nightly continuous positive airway pressure treatment of obstructive sleep apnea improves glucose metabolism in patients with prediabetes. A randomized controlled trial. Am J Respir Crit Care Med. 2015;192(1):96-105.

72. Babu AR, Herdegen J, Fogelfeld L, et al. Type 2 diabetes, glycemic control, and continuous positive airway pressure in obstructive sleep apnea. Arch Intern Med. 2005;165(4):447-452.

73. Sopkova Z, Dorkova Z, Tkacova R. Predictors of compliance with continuous positive airway pressure treatment in patients with obstructive sleep apnea and metabolic syndrome. Wien Klin Wochenschr. 2009;121(11):398-404.

74. Steiropoulos P, Papanas N, Nena E, et al. Continuous positive airway pressure treatment in patients with sleep apnoea: does it really improve glucose metabolism? Curr Diabetes Rev. 2010;6(3):156-166.

75. Stoohs RA, Facchini F, Guilleminault C. Insulin resistance and sleepdisordered breathing in healthy humans. American journal of respiratory and critical care medicine. 1996;154(1):170-174.

76. Brooks B, Cistulli PA, Borkman M, et al. Obstructive sleep apnea in obese non insulin-dependent diabetic patients: effect of continuous positive airway pressure treatment on insulin responsiveness. $J$ Clin Endocrinol Metab. 1994;79(6):1681-1685.

77. Young T, Finn L, Peppard PE, et al. Sleep disordered breathing and mortality: eighteen-year follow-up of the Wisconsin sleep cohort. Sleep. 2008;31(8):1071-1078.

78. Yu J, Zhou Z, Mc Evoy RD, et al. Association of positive airway pressure with cardiovascular events and death in adults with sleep apnea: a systematic review and meta-analysis. JAMA. 2017;318(2):156-166.

79. Gangwisch J, Heymsfield S, Boden-Albala B, et al. Sleep duration as a risk factor for diabetes incidence in a large US sample. Sleep. 2007;30(12):1667-1673.

80. Clarenbach CF, West SD, Kohler M. Is obstructive sleep apnea a risk factor for diabetes? Discov Med. 2011;12(62):17-24.
81. Cleator IG, Birmingham CL, Kovacevic S, et al. Long-term effect of ileogastrostomy surgery for morbid obesity on diabetes mellitus and sleep apnea. Obes Surg. 2006;16(10):1337-1341.

82. Greco C, Spallone V. Obstructive Sleep Apnoea Syndrome and Diabetes. Fortuitous Association or Interaction? Curr Diabetes Rev. 2015;12(2):129-55

83. Marshall NS, Wong KK, Phillips CL, et al . Is sleep apnea an independent risk factor for prevalent and incident diabetes in the Busselton Health Study? J Clin Sleep Med. 2009;5(1):15-20.

84. Hui P, Zhao L, Xie Y, et al. Nocturnal Hypoxemia Causes Hyperglycemia in Patients with Obstructive Sleep Apnea and Type 2 Diabetes Mellitus. Am J Med Sci. 2016;351(2):160-168.

85. Ceccato F, Bernkopf E, Scaroni C. Sleep apnea syndrome in endocrine clinics. J Endocrinal Invest. 2015;38(8):827-834.

86. Appleton SL, Vakulin A, Mc Evoy RD, et al. Nocturnal Hypoxemia and Severe Obstructive Sleep Apnea are Associated with Incident Type 2 Diabetes in a Population Cohort of Men. J Clin Sleep Med. 2015;11(6):609-614

87. Levy P, Bonsignore MR, Eckel J. Sleep, sleep-disordered breathing and metabolic consequences. Eur Respir J. 2009;34(1):243-260.

88. Li KK, Kushida C, Powell NB, et al. Obstructive sleep apnea syndrome: a comparison between Far-East Asian and white men. The Laryngoscope. 2000;110(10):1689-1693.

89. Seetho IW, Wilding JP. Sleep-disordered breathing, type 2 diabetes and the metabolic syndrome. Chron Respir Dis. 2014;11(4):257-275.

90. Chen L, Pei JH, Chen HM . Effects of continuous positive airway pressure treatment on glycaemic control and insulin sensitivity in patients with obstructive sleep apnoea and type 2 diabetes: a meta-analysis. Arch Med Sci. 2014;10(4):637-642.

91. Feng Y, Zhang Z, Dong ZZ. Effects of continuous positive airway pressure therapy on glycaemic control, insulin sensitivity and body mass index in patients with obstructive sleep apnoea and type 2 diabetes: a systematic review and meta-analysis. NPJ Prim Care Respir Med. 2015:15005.

92. Flegal KM, Kruszon-Moran D, Carroll MD, et al. Trends in obesity among adults in the United States, 2005 to 2014. JAMA. 2016;315(21):2284-91.

93. Senaratna CV, English DR, Currier D, et al. Sleep apnoea in Australian men: disease burden, co-morbidities, and correlates from the Australian longitudinal study on male health. BMC Public Health. 2016;16(Suppl 3): 1029 . 